\title{
Left Ventricular Basal Anterolateral Segment
}

National Cancer Institute

\section{Source}

National Cancer Institute. Left Ventricular Basal Anterolateral Segment. NCI Thesaurus. Code C127656.

The anterolateral portion of the basal division of the left ventricular myocardium as determined using the AHA 17-Segment Model (Cerqueira et al., 2002). 